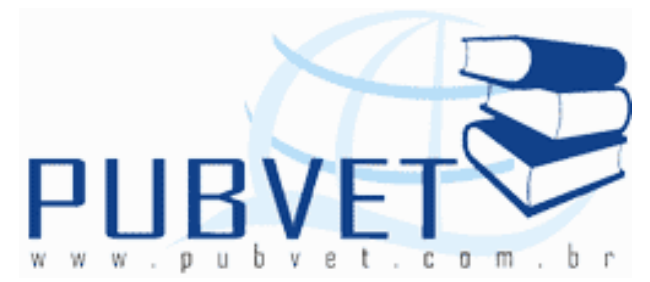

PUBVET, Publicações em Medicina Veterinária e Zootecnia.

\title{
Proteinograma sérico de Tartarugas-da-Amazônia (Podocnemis expansa, Schweigger - 1812) - Testudines, Podocnemididae
}

\author{
André Luiz Quagliatto Santos ${ }^{1}$, Antonio Vicente Mundim ${ }^{1}$, Lorena Tannús \\ Menezes $^{2}$, Arthur Paulino Sanzo Kaminishi ${ }^{2}$, Tatiana Grillo Leonardo ${ }^{2}$, Liliane \\ Rangel Nascimento ${ }^{2}$
}

Laboratório de Ensino e Pesquisas em Animais Silvestres - LAPAS, FAMEV/UFU, e-mail: quagliatto@famev.ufu.br 1. Docente. 2. Mestrandos.

\section{Resumo}

O objetivo desta pesquisa foi obter informações sobre o proteinograma sérico de tartarugas Podocnemis expansa mantidas em um laboratório de pesquisa. Foram colhidas, por venipuntura do seio vertebral caudal, amostras de sangue de 25 animais mantidos em tanques no Laboratório de Pesquisa em Animais Silvestres (LAPAS), no município de Uberlândia, MG, Brasil. Após colhidas, as amostras de sangue foram transferidas rapidamente para frascos vacutainer sem anticoagulante e encaminhadas ao laboratório Clínico da Faculdade de Medicina Veterinária (FAMEV) da Universidade Federal de Uberlândia (UFU). As análises foram processadas colorimetricamente e obtiveram-se os valores médios: proteínas totais $4,79 \pm 0,73 \mathrm{~g} / \mathrm{dL}$, albumina $3,11 \pm 0,72 \mathrm{~g} / \mathrm{dL}$, globulinas $1,67 \pm 0,84 \mathrm{~g} / \mathrm{dL}$ e relação albumina/globulina (A/G) $2,91 \pm 2,75$. Os valorses bioquímicos da espécie estudada são escassos, desta maneira os dados que foram apresentados auxiliam no estabelecimento de um padrão de referência 
para Podocnemis expansa mantidas em laboratório de pesquisa, bem como pode ser base para novos estudos.

Palavras-chave:Albumina, bioquímica sérica, répteis, globulina, proteína.

\title{
Serum protein concentration in South American River Turtle (Podocnemis expansa, Schweigger - 1812) -Testudines, Podocnemididae
}

\begin{abstract}
The purpose of this study was to obtain information of the serum protein concentrations in Podocnemis expansa. For this experiment, 25 animals from the laboratory of wild animals research (LAPAS) were used. The blood was collected from the vertebral sinus and transferred to vacutainer tubes without anticoagulants. The samples were processeded at Clinical Lab in the Veterinary Hospital of the Federal University of Uberlândia.The medium values found for total proteins, albumine, globulines and albumin/globulin ratio $(A / G)$ were $4.79 \pm 0.73 \mathrm{~g} / \mathrm{dL} ; \quad 3.11 \pm 0.72 \mathrm{~g} / \mathrm{dL} ; \quad 1.67 \pm 0.84 \mathrm{mg} / \mathrm{dL}$ and $2.91 \pm 2.75$, respectively. This study represents a contribution to the referential serum protein values of the $P$. expansa.
\end{abstract}

Keywords: Albumin, serum biochemistry, reptiles, globulin, protein.

\section{INTRODUÇÃO}

Os quelônios são um grupo de répteis que se tornam cada dia mais utilizados como animais de companhia, fazendo-se necessário o conhecimento por parte dos clínicos de tudo que diz respeito a sua exploração racional. Em conseqüência disto, associado à queda do número de exemplares em determinadas regiões, tem surgido interesse pela sua reprodução em cativeiro e necessidade de conhecimentos mais aprofundados sobre as doenças que acometem estas espécies (MURO et al., 1994). 
SANTOS, A.L.Q. et al. Proteinograma sérico de Tartarugas-da-Amazônia (Podocnemis expansa, Schweigger - 1812) - Testudines, Podocnemididae. PUBVET, Londrina, V. 5, N. 16, Ed. 163, Art. 1104, 2011.

Uma das mais freqüentes causas de processos patológicos nas tartarugas, segundo BORDEAU (1988) é a péssima condição de manejo a que na maioria das vezes são submetidas. A tartaruga-da-amazônia está legalmente liberada à criação comercial, pelo seu potencial para a exploração zootécnica. Com isso, o desenvolvimento de sistemas de criação pode contribuir para a diminuição da pressão sobre os animais de vida livre (CENAQUA, 2000).

Dentre as principais doenças que acometem este répteis podemos citar: afeç̧ões hepáticas de etiologias variadas, rinites, pneumonias, broncopneumonias infecciosas, endoparasitoses e hemoparasitoses, as quais podem ser responsáveis por certos graus de anemia e até mesmo a morte (LAWRENCE e NEEDHAM, 1985; BORDEAU, 1988 e 1989). A avaliação hematológica é de grande valor na investigação de doenças, e pode mostrar alterações fisiológicas entre animais de vida livre e aqueles criados em cativeiro (DIVERS; REDMAYNE; e AVES, 1996).

Fatores como idade, tamanho, sexo, estação do ano, saúde, habitat e dieta podem afetar os parâmetros de maneira geral, dificultando o estabelecimento de valores séricos de referência e comparações entre indivíduos e populações (GOTTDENKER e JACOBSON,1995). Extraordinárias variações nos sais metabólicos podem ocorrer decorrentes de variáveis como a alimentação, tempo de apnéia, variações na temperatura corporal, disponibilidade de água, ciclo reprodutivo, estação do ano, e com a hibernação (SAMOUR et al., 1986; HENEN, 1997; CHRISTOPHER et al., 1999). Na maioria das vezes as informações que se pode obter são mínimas e inadequadas para o estabelecimento de um diagnóstico.

Tendo em vista a escassez de estudos sobre os constituintes bioquímicos séricos em quelônios da fauna brasileira e o grande valor destes como métodos auxiliares no diagnóstico de doenças, na avaliação do manejo, das condições de saúde e adaptação dos mesmos em ambientes de laboratório, objetivou-se no presente estudo mensurar as variações de alguns constituintes bioquímicos séricos de Podocnemis expansa mantidas em laboratório 
SANTOS, A.L.Q. et al. Proteinograma sérico de Tartarugas-da-Amazônia (Podocnemis expansa, Schweigger - 1812) - Testudines, Podocnemididae. PUBVET, Londrina, V. 5, N. 16, Ed. 163, Art. 1104, 2011.

acrescentando subsídios para o melhor desenvolvimento da Patologia Clínica para a espécie em questão.

\section{MATERIAL E MÉTODO}

Local e animais: Foram utilizados 25 animais, fêmeas, oriundos do Laboratório de Pesquisa em Animais Silvestres (LAPAS) da Faculdade de Medicina Veterinária (FAMEV), Universidade Federal de Uberlândia (UFU). Os animais, com idade entre 2 e 5 anos estavam alojados em tanques de fibra de vidro com água corrente e aquecedores elétricos, mantendo-se a temperatura entre $26^{\circ}$ e $28^{\circ}$. A alimentação destes animais era constituída de ração comercial com $24 \%$ de proteína bruta e ocasionalmente recebiam frutas, verduras e legumes da estação.

Reagentes e aparelho: As análises bioquímicas foram processadas colorimetricamente a $37^{\circ} \mathrm{C}$ em analisador automático Cobas Mira, no Laboratório Clínico Veterinário da FAMEV, UFU, utilizando kits Labtest. Analizaram-se os níveis séricos de albumina e proteínas totais pelos métodos de bromacresol e biureto respectivamente.

Os valores séricos da globulina foram obtidos através da diferença entre proteínas totais e albumina e pela divisão dos valores da albumina pelos valores da globulina obteve-se a relação albumina/globulina.

Colheita das amostras: Foram colhidos, de cada animal, aproximadamente 4 $\mathrm{mL}$ de sangue em seringas descartáveis, no seio dorsal na região da cauda (FIGURA 1). O sangue foi transferido imediatamente para frascos sem anticoagulante. As amostras foram transportadas para o Laboratório Clínico Veterinário, FAMEV, UFU. 


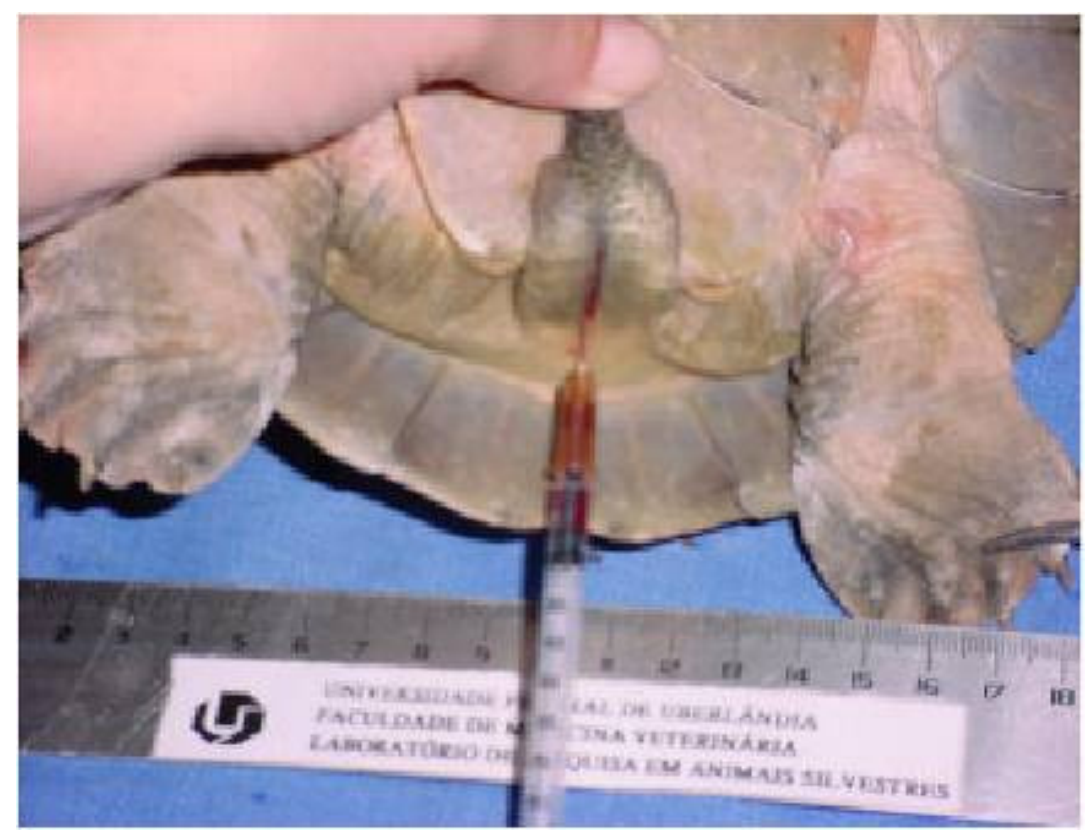

FIGURA 1: Fotografia de colheita de sangue na cauda de Podcnemis expansa.

Processamento das análises: No Laboratório Clínico Veterinário da FAMEV, UFU, os soros obtidos das amostras foram submetidos a análises para verificação dos níveis séricos de proteínas totais, albumina, globulinas.

Análise estatística: Com o objetivo de verificar a existência ou não de correlações significantes entre as massas corporais dos animais analisados e os vários constituintes bioquímicos sanguíneos obtidos, foi aplicada a prova não paramétrica Coeficiente de Correlação por Postos de Spearman às variáveis: relação albumina/globulina, uma vez que estas distribuições não são normais. Quanto às outras variáveis, foi aplicado o Coeficiente de Correlação de Pearson. O nível de significância foi estabelecido em $5 \%(p<0,05)$, em uma prova bilateral (TABELA 3).

\section{RESULTADOS E DISCUSSÃO}

A variação dos valores bioquímicos séricos de Tartarugas-da-Amazônia desta pesquisa está apresentada na TABELA 1. Devido à escassez de trabalhos com a espécie Podocnemis expansa, os valores das variáveis analisadas no 
SANTOS, A.L.Q. et al. Proteinograma sérico de Tartarugas-da-Amazônia (Podocnemis expansa, Schweigger - 1812) - Testudines, Podocnemididae. PUBVET, Londrina, V. 5, N. 16, Ed. 163, Art. 1104, 2011.

presente estudo foram confrontados com outras espécies de quelônios (jabutis e tartarugas lacustres e marinhas). Observa-se que os níveis das proteínas totais dos animais do presente estudo foram superiores aos propostos por ROSSKOPF JUNIOR (1982) no jabuti do deserto californiano Gopherus agassizzi 2,2 a 5,0 g/dL, GHEBREMESKEL et al. (1991) em jabutis gigantes

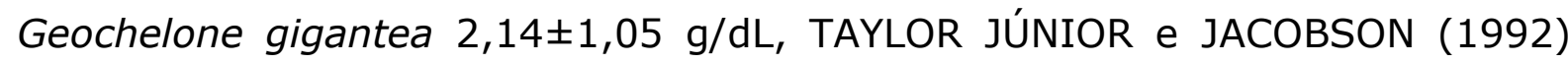

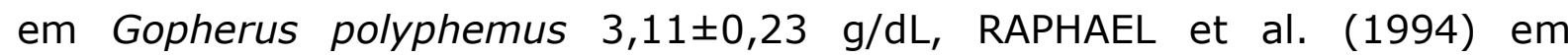
Malacochersus tornieri 2,4 a 4,1 g/dL, MADER (1996) também em Malacochersus tornieri 3,1 g/dL, MUNDIM et al. (1999) em Podocnemis expansa em seu habitat natural $3,23 \pm 0,50 \mathrm{~g} / \mathrm{dL}$, sendo próximos aos encontrados por SAMOUR et al. (1986) em jabutis gigantes, Geochelone spp.


SANTOS et al. (2005) em Podocnemis expansa 4,43 $\pm 0,55$, FERREIRA (2002) em jabutis sul americanos Geochelone carbonaria e Geochelone denticulata $3,98 \pm 1,57 \mathrm{~g} / \mathrm{dL}$, e inferior ao observado por BOLTEN e BJORNDAL (1992) na tartaruga marinha Chelonia mydas $5,1 \pm 0,8 \mathrm{~g} / \mathrm{dL}$.

TABELA 1 - Médias, desvio padrão e amplitude de variação do proteinorama sérico de tartarugas da amazônia (Podocnemis expansa), mantidas em laboratório, Uberlândia, MG, 2007.

\begin{tabular}{llllrr}
\hline Constituinte Protéico & Unidade & Média & Desvio & \multicolumn{3}{c}{$\begin{array}{c}\text { Amplitude de Variação } \\
\text { Mínimo }\end{array}$} \\
& & & \multicolumn{2}{c}{ Máximo } \\
\hline Proteínas Totais & $\mathrm{g} / \mathrm{dL}$ & 4,79 & 0,73 & 3,40 & 6,35 \\
Albumina & $\mathrm{g} / \mathrm{dL}$ & 3,11 & 0,72 & 2,00 & 4,98 \\
Globulina & $\mathrm{g} / \mathrm{dL}$ & 1,67 & 0,84 & 0,41 & 2,95 \\
Relaçao A/G & $\mathrm{g} / \mathrm{dL}$ & 2,91 & 2,75 & 0,68 & 13,10 \\
\hline
\end{tabular}

Com relação à albumina, seus valores foram superiores aos observados por TAYLOR JÚNIOR e JACOBSON (1992), estes encontraram 1,52 $\pm 0,14 \mathrm{~g} / \mathrm{dL}$, SAMOUR et al. (1986) $1,54 \pm 0,64 \mathrm{~g} / \mathrm{dL}$, MARKS e CINTINO (1990) $1,54 \pm 0,64$ $\mathrm{g} / \mathrm{dL}$, GHEBREMESKEL et al. (1991) 0,78 $\pm 0,4 \mathrm{~g} / \mathrm{dL}$, BOLTEN e BJORNDAL (1992) 1,5 $\pm 0,2 \mathrm{~g} / \mathrm{dL}$, RAPHAEL et al. (1994) 1,2 a 2,1 g/dL, MADER (1996)

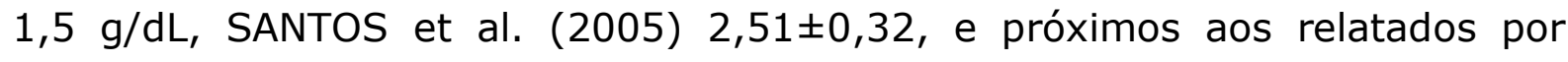


SANTOS, A.L.Q. et al. Proteinograma sérico de Tartarugas-da-Amazônia (Podocnemis expansa, Schweigger - 1812) - Testudines, Podocnemididae. PUBVET, Londrina, V. 5, N. 16, Ed. 163, Art. 1104, 2011.

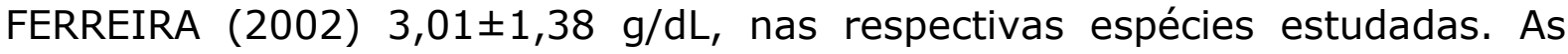
globulinas apresentaram valores próximos aos observados por RAPHAEL et al. (1994) 1,2 a 2,0, e inferiores aos de SAMOUR et al. (1986) 2,6 $6 \pm 1,2 \mathrm{~g} / \mathrm{dL}$,

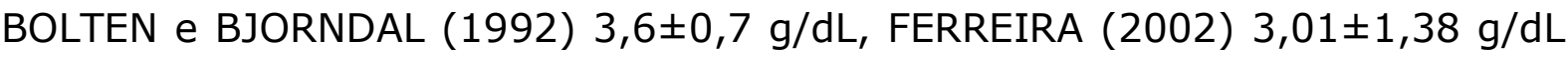
e SANTOS et al. (2005) 1,92 $\pm 0,35$. A relação albumina/globulina apresentou valores superiores aos encontrados por BOLTEN e BJORNDAL (1992) $0,4 \pm 0,1$ $\mathrm{g} / \mathrm{dL}$, FERREIRA (2002) 0,38 $\pm 0,21 \mathrm{~g} / \mathrm{dL}$ e SANTOS et al. (2005) 1,55 $\pm 1,46$.

As diferenças ocorridas entre os níveis dos constituintes protéicos do sangue da Podocnemis expansa deste estudo, quando confrontados com os dados de outros pesquisadores se devem, provavelmente, às diferentes espécies estudadas, aos diferentes habitats, aos diferentes tipos de alimentação e mesmo a grande variação de idade, já que geralmente são animais que possuem uma vida muito longa. Alguns constituintes avaliados apresentavam grande amplitude de variação, fato que também pode ser confirmado nas pesquisas aqui discutidas. Pode ser que algumas destas variações sejam em decorrência das diferenças de idade, variações fisiológicas, estresse durante a manipulação dos animais, e principalmente: temperatura; deve-se lembrar que diferenças de temperatura no ambiente influenciam diretamente o metabolismo de répteis. A relação entre a variação dos componentes bioquímicos séricos das Tartarugas-da-Amazônia com o seu peso corporal segue na TABELA 2.

TABELA 2: Médias e desvios padrão das amplitudes de variação da relação entre os constituintes protéicos séricos de tartarugas da amazônia (Podocnemis expansa) mantidas em laboratório e seu peso corporal (entre 1,25 e 6,2kg), Uberlândia, MG, 2007.

\begin{tabular}{lccc}
\hline Constituintes Protéicos & $\mathbf{1 , 2 5} \mathbf{~ a ~ 2 , 2 0 ~ k g}$ & $\mathbf{2 , 2 0} \mathbf{a ~ 3 , 0 ~} \mathbf{~ g}$ & $\mathbf{3 , 0} \mathbf{~ a ~ 6 , 2 0 ~} \mathbf{~ g g}$ \\
\hline Albumina & $3,37 \pm 0,97$ & $3,11 \pm 0,42$ & $2,87 \pm 0,74$ \\
Globulina & $1,1 \pm 0,71$ & $2,01 \pm 0,71$ & $1,87 \pm 0,87$ \\
Relação ALB/GLOB & $4,73 \pm 3,81$ & $1,78 \pm 0,80$ & $2,35 \pm 2,21$ \\
Proteínas Totais & $4,47 \pm 0,8$ & $5,12 \pm 0,66$ & $4,74 \pm 0,68$ \\
\hline
\end{tabular}


SANTOS, A.L.Q. et al. Proteinograma sérico de Tartarugas-da-Amazônia (Podocnemis expansa, Schweigger - 1812) - Testudines, Podocnemididae. PUBVET, Londrina, V. 5, N. 16, Ed. 163, Art. 1104, 2011.

De acordo com os resultados demonstrados na tabela acima, foram encontradas correlações negativas significantes entre a massa corporal e os valores da variável albumina/globulina indicando que quando os valores de massa corporal aumentam, os valores da variável diminui, mostrando-se assim inversamente proporcional.

TABELA 3 - Valores de "r","rs" e probabilidades das correlações de Spearman e Pearson entre massa corporais $(\mathrm{kg}) \times$ constituintes protéicos séricos de tartaruga da amazônia (Podocnemis expansa) mantidas em laboratório. ** significância $(p<0,05)$.

\begin{tabular}{lcccc}
\hline Constituintes Protéicos & Valores de "r" & P - "r" & Valores de "rs" & P - "rs" \\
\hline Proteínas totais & $-0,2228$ & 0,2840 & 0,0301 & 0,8866 \\
Albumina & $-0,2281$ & 0,2730 & 0,2481 & 0,2318 \\
Globulina & 0,0001 & 1,0000 & 0,2668 & 0,1973 \\
Relação A/G & 0,0113 & 0,9570 & $-0,2586$ & 0,2120 \\
\hline
\end{tabular}

\section{CONCLUSÕES}

Os resultados obtidos não apresentam grandes diferenças dos valores de outras espécies de quelônios. Os resultados do presente estudo contribuem para a obtenção dos valores de referência para Podocnemis expansa mantidas em ambiente de laboratório.

\section{REFERÊNCIAS}

BOLTEN, A.B.; BJORNDAL, K.A. Blood profiles for a wild population of green turtles (Chelonia mydas) in the Southern Bahamas: size-specific and sex-specific relationships. Journal of Wildlife Diseases, Ames, v.28, n.3, p.407-413, 1992.

BORDEAU, P. Pathologie des tortues 3re partie: affections respiratoires, autres affections d'organes et thérapeutique. Point Vétérinaire, Maison Alfort, v.21, n.119, p.45-62, 1989.

BORDEAU, P. Pathologie des tortues 1re partie: examen clinique et maladies générales. Point Vétérinaire, Maison Alfort, v.20, n.117, p.761-775, 1988.

CENAQUA. Atividades da área de criação em cativeiro no exercício de 2000. Goiânia: Centro Nacional dos Quelônios da Amazônia. IBAMA, 2000. 20p. Relatório. 
SANTOS, A.L.Q. et al. Proteinograma sérico de Tartarugas-da-Amazônia (Podocnemis expansa, Schweigger - 1812) - Testudines, Podocnemididae. PUBVET, Londrina, V. 5, N. 16, Ed. 163, Art. 1104, 2011.

CHRISTOPHER, M.M.; BERRY, K.H.; WALLIS, I.R.; NAGY, K.A.; HENEN, B.T.; PETERSON, C.C. Reference intervals and physiologic alterations in hematological and biochemical values of free-raging desert tortoises in Mojave desert. Journal of Wildlife Diseases, Ames, v.35, n.2, p.212-238, 1999.

DIVERS, S. J.; REDMAYNE, G.; AVES, K. Haematological and biochemical of 10 green iguanas (Iguana iguana). The Veterinary Record, London, v. 138, n. 3, p. 203 - 205, 1996.

FERREIRA, A.B. Perfil bioquímico sanguíneo de jabutis (Geochelone carbonaria e Geochelone denticulata). Uberlândia, 2002, 23p. Graduação (Medicina Veterinária), Faculdade de Medicina Veterinária, Universidade Federal de Uberlândia.

GHEBREMESKEL, K.; WILLIAMS, G.; SPRATT, D.; SAMOUR, H.J. Plasma biochemistry of freeliving giant tortoise (Geochelone gigantea) on Curieuse Island (Republic of Seycheles). Comparative Biochemistry and Physiology, New York, v.99A, n.1/2, p.65-67, 1991.

GOTTDENKER, N. L.; JACOBSON, E. R. Effect of venipuncture sites on hematological and clinical biochemical values in desert tortoises (Gopherus agassizii). American Journal of Veterinary Research, Giza, v. 56, n. 1, p. 19 - 21, 1995.

HENEN, B.T Seasonal and annual energy budgets of female desert tortoises (Gopherus agassizzi). Ecology, Tempe, v.78, n.2, p.283-296, 1997.

LAWRENCE, K.; NEEDHAM, J.R. Rhinitis in long term captive Mediterranean tortoises ( $T$. graeca and T.hermanni). Veterinary Record, London, v.117, n. 25/26, p.662-664, 1985.

MADER, D.R. Reptile Medicine and Surgery. Philadelphia: W.B. Saunders, 1996. 512p.

MARKS, S.K.; CINTINO, S.B. Hematology and serum chemistry of the radiated tortoise (Testudo radiata).

Journal of Zoo and WildLife Medicine, Lawrence, v.21, n.3, p.342-344, 1990.

MUNDIM, A.V.; QUEIROZ, R.P.; SANTOS, A.L.Q.; BELETTI, M.E.; LUZ, V.L.F. Bioquímica sanguínea da Tartaruga da Amazônia (Podocnemis expansa) em seu habitat natural. Bioscience Journal, Uberlândia, v.15, n.2, p.35-43, 1999.

MURO, J.; CUENCA, R.; VIÑAS, L.; LAVIN, S. Interes del hemograma en la clínica de quelonis. Veterinária Praxis, Caracas, v.9, n.3, p.24-29, 1994.

RAPHAEL, B.L.; KLEMENS, M.W.; MOEHLMANN, P.; DIERENFELD, E.; KARESH, W.B. Blood values in freeranging pancake tortoise (Malacochersus tornieri). Journal of Zoo and WildLife Medicine, Lawrence, v.25, n.1, p.63-67, 1994.

ROSSKOPF JUNIOR, W.J. Normal hemogram and blood chemistry values for California desert tortoises. The Veterinary Clinics of North America, Small Animal Practice, Philadelphia, v.77, n.1, p.85-87, 1982.

SAMOUR, H.J.; HAWKEY, C.M.; PUGSLEY, S.; BALL, D. Clinical and pathological findings related to malnutrition and husbandry in captive giant tortoises (Geochelone spp.). Veterinary Record, London, v.118, n. 11, p.299-302, 1986.

SANTOS, A.L.Q.; MALTA, T.S.; MUNDIM, A.V.; ALVES JÚNIOR, J.R.F.; CARVALHO, S.F.M. Variação dos constituintes bioquímicos sanguíneos de tartarugas-da-amazônia (podocnemis 
SANTOS, A.L.Q. et al. Proteinograma sérico de Tartarugas-da-Amazônia (Podocnemis expansa, Schweigger - 1812) - Testudines, Podocnemididae. PUBVET, Londrina, V. 5, N. 16, Ed. 163, Art. 1104, 2011.

expansa, schweigger - 1812) (testudinata) mantidas em criatório comercial. Archives of Veterinary Science, Belo Horizonte, v. 10, n. 3, p. 1-8, 2005.

TAYLOR JUNIOR, R.W.; JACOBSON, E.R. Hematology and serum chemistry of the gopher tortoise, Gopherus polyphemus. Comparative Biochemistry and Physiology, New York, v.103A, n.2, p.275-278, 1992. 